\title{
BALLOON TRAWL: A SAFE AND EFFECTVE WAY OF REMOVING COMMON BILE DUCT EMBEDDED STENTS
}

\author{
Shafqat Mehmood, Faisal Zeb \\ Departments of Internal Medicine, Shaukat Khanum Memorial Cancer Hospital and Research Centre Lahore, Pakistan \\ Received: 8 April 2015 / Accepted: 23 April 2015
}

\begin{abstract}
Biliary stenting has been used since the 1970s to relieve biliary obstruction for a variety of causes including benign and malignant biliary strictures. Migration of stents proximally into the biliary tree or distally into the intestinal tract is relatively uncommon. We report a case of a 64-year-old female with a peri-ampullary tumour, who had symptomatic obstructive jaundice following endoscopic retrograde cholangiopancreatography and plastic stent insertion. Follow-up imaging showed proximal migration of the plastic stent and blockage of the distal common bile duct (CBD) secondary to the periampullary tumour. The biliary stent was safely removed endoscopically using balloon trawl. This case highlights that, while biliary stenting for strictures is generally safe and effective, stent migration to proximal CBD can occur. Balloon trawl is safe and effective way of removing such stents.
\end{abstract}

Key words: Biliary stricture, common bile duct, endoscopic retrograde cholangiopancreatography, periampullary tumour, stents

\section{Introduction}

Biliary stents are in use for quite a few decades for biliary obstruction. A case of migration of a stent is presented here as a potential complication.

\section{Case Report}

A 64-year-old female patient was seen in the outpatient department complaining of right upper quadrant pain. She had undergone endoscopic retrograde cholangiopancreatography (ERCP) and biliary stenting for right upper quadrant pain and jaundice a year previously and then lost to follow-up. A biphasic computed tomography scan of the abdomen was performed, which showed a lesion at the ampulla measuring approximately $1.8 \mathrm{~cm}$ in size. The previously placed stent was seen to have migrated upwards, into the proximal common bile duct (CBD), above the lesion, resulting in mild intrahepatic biliary dilatation without evidence of pneumobilia. A diagnosis of a proximally migrated CBD stent was made and it was decided to perform an ERCP and stent change. A side-viewing endoscope was passed in standard fashion to the duodenum. The CBD was cannulated

Correspondence: Dr. Shafqat Mehmood, Department of Internal Medicine, Shaukat Khanum Memorial Cancer Hospital and Research Centre, Johar Town, Lahore, Pakistan.

Email: smehmood@skm.org.pk over a guide wire and a cholangiogram was performed, which confirmed proximal stent migration [Figure 1].

A Duralon (Wilson-Cook ${ }^{\mathrm{R}}$ ) occlusion balloon was passed above the stent and inflated to $18 \mathrm{~mm}$, after which the stent was removed by balloon trawl [Figures 2 and 3].

A repeat cholangiogram was performed, which revealed a dilated biliary tree. A $7 \mathrm{~cm} 7 \mathrm{Fr}$ double pigtail plastic biliary stent was inserted with good biliary drainage. The patient tolerated the procedure well and was discharged home the same day.

\section{Discussion}

Biliary stent migration is reported to occur in a minority of patients, but its management can be technically difficult for endoscopists. ${ }^{[1]}$ Available data suggest that proximal or distal stent migration occurs in $5-10 \%$ of patients. ${ }^{[2]}$ The risk of stent migration appears to be higher for benign compared to malignant biliary strictures. ${ }^{[3,4]}$ Migrated stents can most often be retrieved using a grasping basket, inflation of a balloon extraction catheter alongside or above the stent, cannulation of the stent or grasping it with a rat-tooth forceps. ${ }^{[4,5,6]}$

Lahoti et al. were able to retrieve these stents in 34 of 38 patients using a Dormia basket or balloon. ${ }^{[5]}$ Similarly, 


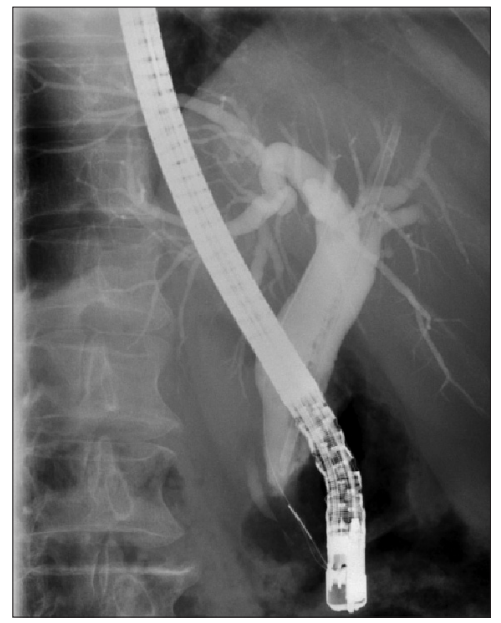

Figure 1: Endoscopic retrograde cholangiopancreatography image showing dilated common bile duct (CBD) and a plastic stent entirely within the $\mathrm{CBD}$, as indicated by the arrows.

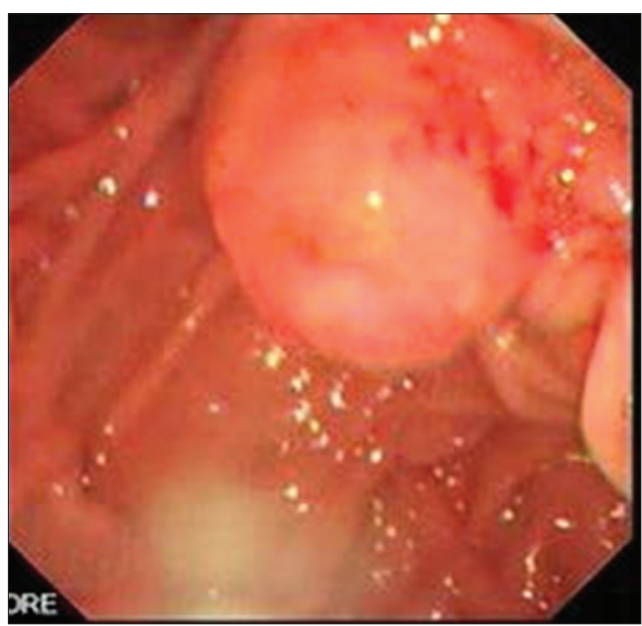

Figure 2: Endoscopic image of the ampulla, where the previously placed stent was not visualised

Panagiotis et al. were able to retrieve proximally migrated biliary stents in 15 of the 21 patients using balloon trawl in combination with the other techniques. ${ }^{[7]}$ While the removal of proximally migrated stents has been well described, this case report further confirms that balloon trawl is safe and effective in the removal of proximally migrated stents and should be considered for these stents.

In summary, this is a case of a 64-year-old female who underwent ERCP and plastic stent insertion for obstructive jaundice. Follow-up imaging after a year showed proximal migration of stent with resulting biliary dilatation. During ERCP, the stent was retrieved by balloon trawl. This case

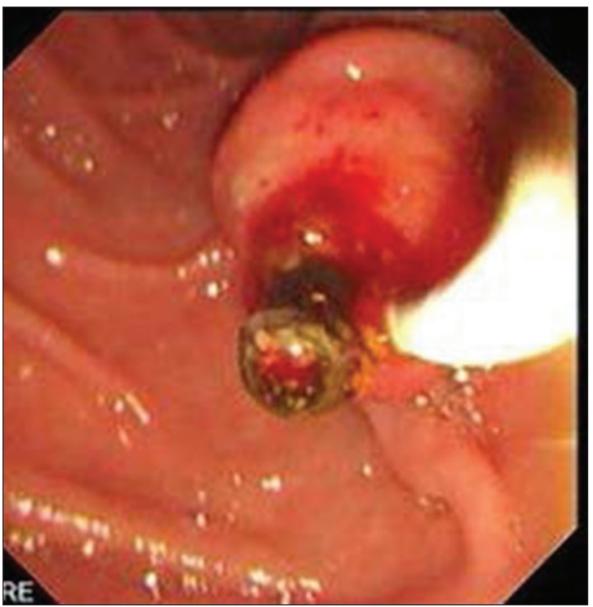

Figure 3: Plastic stent removal with a Duralon occlusion balloon

highlights that, while biliary stents are very effective in the management of choledocholithiasis, they can migrate and their removal can be challenging for endoscopists. These challenges can be overwhelmed using various techniques including balloon trawl.

\section{Conflict of Interest}

The authors declare that they have no conflict of interest.

\section{References}

1. Lammer J, Neumayer K. Biliary drainage endoprostheses: Experience with 201 placements. Radiology 1986;159: 625-62.

2. Tarnasky PR, Cotton PB, Baillie J, et al. Proximal migration of biliary stents: Attempted endoscopic retrieval in forty-one patients. Gastrointest Endosc 1995;42:513-20.

3. Arhan M, Odemiş B, Parlak E, et al. Migration of biliary plastic stents: Experience of a tertiary center. Surg Endosc 2009;23: 769-75.

4. Sakai Y, Tsuyuguchi $\mathrm{T}$, Ishihara $\mathrm{T}$, et al. Cholangiopancreatography troubleshooting: The usefulness of endoscopic retrieval of migrated biliary and pancreatic stents. Hepatobiliary Pancreat Dis Int 2009;8:632-7.

5. Lahoti S, Catalano MF, Geenen JE, et al. Endoscopic retrieval of proximally migrated biliary and pancreatic stents: Experience of a large referral center. Gastrointest Endosc 1998;47:486-91.

6. Chaurasia OP, Rauws EA, Fockens P, et al. Endoscopic techniques for retrieval of proximally migrated biliary stents: The Amsterdam experience. Gastrointest Endosc 1999;50: 780-5.

7. Panagiotis K, Jannis K, George P, et al. Migration of plastic biliary stents and endoscopic retrieval: An experience of three referral centers. Surg Laparosc Endosc Percutan Tech 2009;19:217-21. 